\author{
Military Technical College \\ Kobry El-Kobbah, \\ Cairo, Egypt
}

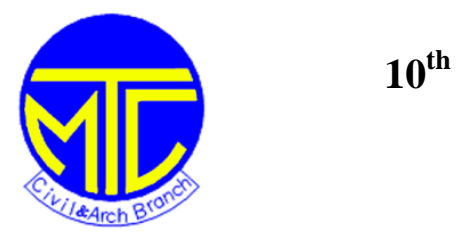

\title{
Blast Mitigation using Rigid Polyurethane Foam to Strengthen Buried Structures
}

\author{
Sherif A. Mazek, Mohamed A. Soliman, Nabil H. Amer \\ Civil Engineering Department, Military Technical College, Cairo, Egypt
}

\begin{abstract}
The use of the rigid polyurethane foam (RPF) to strengthen buried structures against blast terror has great interests from engineering experts in structural retrofitting. The aim of this study is to use the RPF to strengthen the buried structures under blast load. The buried structure is considered to study the RPF as structural retrofitting. The Guowei model (Guowei et al. 2010) is considered as a case study. The finite element analysis (FEA) is also used to model the buried structure under shock wave.

The buried structure performance is studied based on detonating different TNT explosive charges. There is a good agreement between the results obtained by both the Guowei model and the proposed numerical model. The RPF improves the buried structure performance under the blast wave propagation.
\end{abstract}

\section{Keywords}

Displacements; finite element analysis; blast wave; buried structure; TNT explosive charge.

\section{Introduction}

The number of explosive attacks on civilian structures has been recently increased worldwide. Protection of structures subjected to blast load remains quite sophisticated to predict. Current codes and regulations to estimate blast stress wave intensities effect on structures are usually based on some empirical methods due to the extreme complexities of the phenomenon of the blast process (Aimone 1982; Liu and Katsabanis 1997; Fayad 2009; Mohamad 2006; Schueller 1991; Wu et al. 1999; Zhang and Valliappan 1990). These empirical methods were obtained from observations and measurements in field blast tests. The empirical methods tended to overlook the physical laws governing the blast process (Beshara 1994; Smith and Hetherington 1994). Different countries and group of countries apply different design manuals (Remennikov 2003; Gustafsson 1973; Liu and Katsabanis 1997; Technical Manual TM 5-885-1 1986; Technical Manual TM 5-1300 2008).

It is very expensive to conduct field blast tests in every site and sometimes it is impossible to carry out such field tests due to safety and environmental constraints (Dharmasena et al. 2008; Hao et al. 1998). However, a reliable numerical model validated against measured field data is an effective tool to analyze the structure performance under blast effect (Chen and Chen 1996; Dharmasena et al. 2008; Hao et al. 1998). Lu et al. (2005) used a fully coupled numerical model 
to simulate the response of buried concrete structure under subsurface blast. The responses of

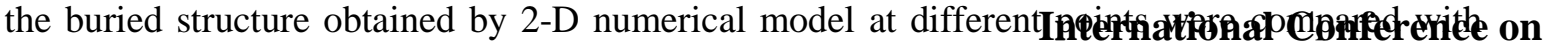

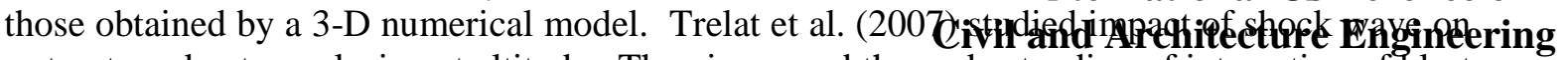
a structure due to explosion at altitude. They improved the understanding of interaction of blast waves with both ground and structure using both the FEA and the experimeetatwerd:2014 et al. (2009) studied craters produced by underground explosions. They discussed the accuracy of numerical simulation of craters produced by underground explosions. Ha et al. (2011) used carbon fibber reinforced polymer (CFRP) to strengthen structures against blast load. They conducted an experimental work on CFRP to strengthen RC panels under blast loading.

Elsayed (2011) used 2-D finite element analysis (FEA) to model two phases of tunneling process. First phase, the excavation phase was responsible to determine the pre-lining rock mass deformations and the reduced in-situ stresses. Second phase, the interaction phase modeled the compatibility of the rock-lining system. The deformations and stresses of the rocklining system and the final rock mass pressure acting on the lining were determined. Cavalaro et al. (2011) analyzed the influence of the contact deficiencies between the segmented tunnel lining during the construction of tunnels and the consequent damage procedure with TBM. They used the finite element analysis to simulate the contact deficiencies.

Darabi et al. (2012) presented an appropriate model to predict the behavior of the tunnel in Tehran No. 3 subway line. They employed empirical methods to determine the variation of radial displacements along the longitudinal direction of a tunnel. They also determined the tunnel deformation using numerical analyses. Kivi et al. (2012) investigated settlement control of large span underground station in Tehran metro using 3-D finite element analysis. They discussed the impact of central beam column (CBC) on the rigidity of the supporting tunnel system. Liu et al. (2012) discussed the ground movement property caused by shield tunneling and expanding construction. Ground movement and construction influence were obtained by numerical model. Wang et al. (2012) used finite element analysis to predict surface settlement above tunnel in clay till. The influence of drainage condition on surface settlement was investigated.

Jongpradist et al. (2013) used three-dimensional elasto-plastic numerical analysis to investigate the influences of tunnel excavation on existing loaded piles. The influence zones affected by driven pile were captured from the finite element analysis. Garner and Coffman (2013) proposed a numerical method based on an acceptable ground surface settlement profile to generate a tunnel system configuration that reproduced the acceptable settlement profile. They presented a brief discussion of existing methods of tunnel settlement analysis and two case studies illustrating the proposed method. Each case study was used to illustrate the use of bifurcated static back calculation - iterative from the finite element model prediction method.

In the present study, 2-D nonlinear FEA is used to study the performance of the buried structure under blast effect, as shown in Fig. 1. Based on the FEA, the performance of the buried structure strengthened by rigid polyurethane foam (RPF) is studied. The RPF is considered as a mitigation system to strengthen the buried structure against blast impact. The Guowei model (Guowei et al. 2010) is used to verify the proposed 2-D finite element model of the buried structure, as shown in Fig. 2. Developing such a numerical method has always been a challenge due to the complicated properties of blasting process and highly nonlinear and strain rate dependent dynamic responses (Hao et al. 1998; Smith and Hetherington 1994). The pressuretime history effect on the buried structure is calculated by the empirical method (Technical Manual TM 5-885-1 1986; Technical Manual TM 5-1300 2008).

In this study, the performance of the buried reinforced concrete (RC) structure is studied with and without using the RPF. The buried RC structures are the most famous structural system used to perform civilian structures (NAT 1993, 1999, 2010).

The constitutive model for this analysis contains elasto-plastic materials. An elasto-plastic model is also employed to represent the RPF layer and the soil media. A nonlinear-inelastic model is also employed to represent the buried RC structure liner. 
Numerical results obtained by the FEA are compared with the data obtained by Guowei model. It shows that the numerical model can well predict the response of the buried structures. Maximum displacements at different locations located at the buried structure strengthened by the RPF are calculated and presented. The study shows the impact of the RPF on the performance of the buried structures.

\section{Numerical model}

The finite element computer program (COSMOS/M) is used in the present study. The finite element model (FEM) takes into account the effects of the vertical overburden pressure, the lateral earth pressure, the non-linear properties of the soil, the non-linear properties of the RPF, the blast effect generated by TNT explosive, and the non-linear properties of the buried RC structure. The soil, the buried structure, the RPF layer, and the interface medium are simulated using appropriate finite elements. Fig. 2 shows the typical section of the buried structure subjected to blast effect (Guowei et al. 2010). The numerical modeling of the buried structure system must reflect the characteristic of the ground continuum, the RPF layer, and the RC structure. In addition, the interface between the soil media and the RC structure should be idealized in the numerical model.

The buried RC structure, the RPF layer, and the soil media are modeled by the modified isotropic damage model and simulated by Lagrange processor (Hao et al. 1998; Wu et al. 1999), as shown in Fig. 3. It should be noted that viscous damping effect is neglected in the numerical simulation as its influence on high velocity explosion-type responses is insignificant (Hao et al. 1998; Wu et al. 1999).

2-D plane strain elements are used for modeling the soil media, the RPF layer, and the buried RC structure, as shown in Fig. 3. Three-node triangular plane strain elements are adopted to simulate the behavior of the soil media, the RPF layer, and the buried structure. The 2-D triangular plane strain element interface is used between the soil media, the RPF layer, and the buried structure to ensure the compatibility conditions at the interface between them as well as the associated stresses and strains along the interface surface.

The horizontal plane at the bottom of the mesh is represented by a rigid bedrock layer and the movement at this plane is restrained in all directions. The vertical boundaries of the 2-D FEM are restrained by roller supports to prevent a movement normal to the boundaries. The movement at the upper horizontal plane is free to simulate a free ground surface. The 2-D finite element mesh is shown in Fig. 3.

The mechanical properties of concrete are Poisson's ratio $v=0.18$; averaged mass density of concrete $2520 \mathrm{~kg} / \mathrm{m}^{3}$; elastic modulus $\mathrm{E}=220 \mathrm{t} / \mathrm{cm}^{2}$; compressive strength $\mathrm{f}_{\mathrm{n}}=500 \mathrm{~kg} / \mathrm{cm}^{2}$; and strain to failure of concrete $\varepsilon_{\mathrm{f}}=0.001$. The shear modulus of the concrete mass depends on the elastic modulus $\mathrm{E}$ and Poisson's ratio $v$.

The mechanical properties of the RPF is tested and obtained by the authors. The mechanical properties of the RPF layer are Poisson's ratio $v=0.3$ and averaged mass density of the RPF layer $=100 \mathrm{~kg} / \mathrm{m}^{3}$. The stress-strain curve used for the RPF is shown in Fig. 4. The shear modulus of the RPF depends on the elastic modulus (E) and Poisson's ratio $(v)$.

\section{Guowei Model (Case Study)}

The buried structure system used in the Guowei model is presented and discussed in the present study as a case study. The diagrammatic scheme of the buried structure system is shown in Fig. 2. The soil media around the buried structure is well graded and compacted dense sand. The buried structure is made of reinforced concrete with 1-meter member thicknesses. The overburden depth of the buried structure is 10 meters. The location of the side TNT explosive is shown in Fig. 2. Guowei et al. (2010) recorded maximum displacement at point (1) located at 
the vertical wall of the buried structure, as shown in Fig. 2. The point (1) is chosen at the midheight of the vertical wall facing the 10-kg TNT explosive, as shown in Fig. 2.

2-D nonlinear numerical model is proposed using the FEA to understand performance of buried structure system based on blast effect. The constitutive model of the surrounding soil media for this analysis utilizes elasto-plastic materials. A yielding function of the Mohr-Coulomb type and a plastic potential function of the Drucker-Prager type are employed (Chen and Mizuno 1990). The soil is idealized as continuum medium with average geotechnical properties of soil commonly found in central Cairo (NAT 1993, 1999, 2010). The nonlinear parameters of sand soil media are presented in Table 1 . Drain analysis is also adopted in this study as the buried structure is constructed through the sand soil media. The maximum displacement at point (1) obtained by the 2-D nonlinear FEA is compared with this obtained by the Guowei model to verify the proposed 2-D FEM.

\section{Boundary Condition of Buried Structure system}

A parametric study is conducted to choose the suitable geometric boundaries of the 2-D numerical model based on the blast effect. The 2-D numerical model should reflect the behavior of the buried structure in the Guowei model. The 10-kg TNT explosive is used in the Guowei model. The 2-D finite element mesh models soil block width and depth in $\mathrm{x}$ and $\mathrm{y}$ directions, respectively, as shown in Fig. 3. The calculated maximum displacements at point (1) located at the buried structure against different model widths are shown in Fig. 5. When the numerical model width exceeds 100 meters there is no change in the estimated maximum displacement at point (1).

The model mesh size is also studied to reflect the performance of the buried structure system based on the 2-D FEA. The element size varied from $2 \mathrm{~m}, 3 \mathrm{~m}$, up to $5 \mathrm{~m}$ along the outer boundary of the soil model block. The element size also varied from $1 \mathrm{~m}, 1.5 \mathrm{~m}$, up to $2.5 \mathrm{~m}$ along the buried structure liner. The calculated maximum displacement at point (1) based on different element sizes is presented in Table 2. The results reveal that as the element size along the outer boundary of the soil model block is smaller than three meters, there is no change in calculated maximum displacement at point (1) due to blast effect. The results also show that as the element size along the buried structure liner is smaller than one meter there is no change in the calculated surface settlement. The element size is chosen to be three meters along the outer boundary of the soil block. The element size is chosen to be one meter along the boundary of the buried structure liner.

\section{Numerical Model Verification}

The shock of the blast wave is generated when the surrounding atmosphere is subjected to an extreme compressive pulse radiating outward from the centre of the TNT explosive. The pressure-time history of a blast wave is illustrated with a general shape by Gaissmaire (2003), as shown in Fig. 6. Transient pressure being greater than ambient pressure is defined as the overpressure $\left(\mathrm{P}_{\mathrm{s}}\right)$ (Smith and Hetherington 1994). The peak overpressure $\left(\mathrm{P}_{\mathrm{s}}\right)$ is the maximum value of the overpressure at a given location. The rise time to peak overpressure is less than microsecond (Baker et al. 1983).

In this study, the CONWEB numerical program (Technical Manual TM 5-885-1 1986) is used to calculate the pressure-time history effect on the buried structure based on different TNT explosive charges. The CONWEB is a collection of conventional weapons effect calculations from the equations and the curves of TM 5-885-1 (1986). The pressure-time histories effect on the buried structure are adopted in the 2-D FEA.

The CONWEB uses the stand-off distance (R) of $4.31 \mathrm{~m}$ to calculate the pressure-time history effect on the buried structure, shown in Fig. 2. Six-kg TNT, eight-kg TNT, ten-kg TNT, twelve-kg TNT explosives are applied at stand-off distance (R) of $4.31 \mathrm{~m}$ to obtain the pressuretime history hitting the buried structure, as shown in Figs. 7 to 10. 
The 2-D FEA is used to obtain the maximum displacement at point (1) (Fig. 2) based on different TNT explosives. The displacement-time history obtained by the FEA is compared with this obtained by the Guowei model based on ten-kg TNT explosive as shown in Fig. 11. The results obtained by the FEA are similar to those obtained by the Guowei model.

\section{Blast Impact on Performance of Buried Structure Strengthened by RPF Layer}

The maximum displacement of the buried structure due to blast load is calculated using the 2-D FEA. The maximum displacements at points (1), (2), and (3) are calculated using the 2-D FEA. The location of the points (1), (2), and (3) are shown in Fig. 12. The FEA is also used to calculate the maximum displacements at different points located at the buried structure strengthened by the RPF layer as mitigation system. The study discusses the impact of the RPF layer on the buried structure performance under blast impact. Based on the 2-D FEA, the thickness of the RPF varied from $0.2 \mathrm{~m}, 0.4 \mathrm{~m}, 0.6 \mathrm{~m}, 0.8 \mathrm{~m}, 1.0 \mathrm{~m}$, up to $1.2 \mathrm{~m}$.

Three cases of the buried structure with and without the RPF layer are studied. At the first case, the buried structure is modeled without the RPF layer. At the second case, the buried structure is modeled with the RPF layer covering the wall facing the side TNT explosive, as shown in Fig. 12. At the third case, the buried structure is modeled using the RPF layer along the whole perimeter of the buried structure, as shown in Fig. 13.

Six-kg TNT, eight-kg TNT, ten-kg TNT, and twelve-kg TNT explosives are used to study the buried structure performance without using the RPF layer (Case 1) at points 1, 2, and 3 (Fig. 12) as well as to discuss the impact of the RPF layer strengthening the wall of the buried structure (Case 2). The TNT explosives are located at 4.31-meter stand-off distance from the samples, as shown in Fig. 12. The pressure- time histories hitting the buried structure are presented in Figs. 7 to 10 . The maximum displacement at points (1), (2), and (3) located at the buried structure are calculated to discuss the impact of the RPF layer. Fig. 14 shows the maximum displacement at point (1) versus the different thicknesses of the RPF layer. Fig. 15 presents the maximum displacements at point (2) versus the different thicknesses of the RPF layer. Fig. 16 presents the maximum displacements at point (3) versus the different thicknesses of the RPF layer. The maximum calculated displacements at points (1), (2), and (3) without the RPF are compared with those strengthened by the RPF layer on these figures. Figures 14, 15, and 16 indicate that the RPF layer strengthening the buried structure leads to reduce the maximum displacement at points (1), (2), and (3). Figs. 17 to 19 show the relation between the different thicknesses of the RPF layer against the reduction percentage in the maximum displacement at points (1), (2), and (3).

Ten-kg TNT explosive is used to discuss the impact of the RPF layer covering either the wall of the buried structure facing the explosive (Case 2) or along the perimeter of the buried structure (Case 3) at points (1), (2), and (3), as shown in Figs. 12 and 13. The maximum displacement at points (1), (2), and (3) are calculated to discuss the impact of the RPF layer. Fig. 20 shows the maximum displacement at point (1) versus the different thicknesses of the RPF layer based on cases 2 and 3. Fig. 21 also presents the comparison between the maximum displacements at point (2) versus the different thicknesses of the RPF layer based on cases 2 and 3. Fig. 22 also presents the comparison between the maximum displacements at point (3) versus the different thicknesses of the RPF layer based on cases 2 and 3. The comparison indicates that the response of the buried structure strengthened by the RPF layer covering the wall facing the TNT explosive is the same as the response of the buried structure strengthened by the RPF layer along the perimeter of the buried structure.

\section{Discussions}

The Guowei model is used to study the performance of the buried structure based on ten-kg TNT explosive charges. The maximum displacement of the buried structure is obtained by the 2-D nonlinear FEA. There is a good agreement between the results by both the Guowei model and the 2-D FEA. The pressure-time history hitting the buried structures is also computed by 
the CONWEB numerical program (Technical Manual TM 5-885-1 1986). The trends of the pressure-time histories obtained by the CONWEB numerical program (Technical Manual TM 5885-1 1986) are the same trend as those presented by Gaissmaire (2003). There is a good agreement between the pressure-time histories obtained by the CONWEB and Gaissmaire (2003).

Fig. 17 shows that the RPF layer reduces the displacement at point (1) by up to $50 \%$ as the thickness of the RPF reaches $100 \mathrm{~cm}$. Fig. 18 also shows that the RPF layer reduces the displacement at point (2) up to $55 \%$ as the thickness of the RPF reaches $100 \mathrm{~cm}$. Fig. 17 reveals that the RPF layer reduces the displacement at point 2 by up to $60 \%$ as the thickness of the RPF reaches $100 \mathrm{~cm}$. As the thickness of the RPF exceeds $100 \mathrm{~cm}$ there is no change in the response of the buried structure.

In general, the buried structures play an important role to resist the blast load. The case of the buried structures strengthened by the RPF layer gives the smallest displacement readings. Therefore, the RPF layer increases the buried RC structure stiffness and then reduces the deformation of the buried RC structure compared to the buried RC structure without the RPF layer. The RPF has a large amount of strain energy which can absorb the kinetic energy of the blast wave propagation. Based on the 2-D FEA, the RPF reduces the maximum displacement of the buried RC structure by up to $50 \%$. Finally, the performance of the buried RC structures is highly dependent on the material properties of the RPF layer which is used as a mitigation system.

\section{Conclusions}

A 2-D nonlinear finite element analysis has been used to predict the performance of buried RC structures with and without PRF layers under the blast effect. The following conclusions can be drawn regarding the performance of the buried structures strengthened by the RPF layer under impact of shock wave propagation through soil media.

- The 2-D nonlinear FEA can be successfully used to analyze and estimate the performance of the buried RC structure based on the Guowei model.

- The pressure-time histories calculated by the CONWEB numerical program (Technical Manual TM 5-885-1 1986) has the same trend as that presented by Gaissmaire (2003).

- The response of the buried structure strengthened by the RPF layer is reduced by up to $50 \%$ with respect to that of the buried structure without the RPF layer.

- The responses of the buried structure strengthened by the RPF layer along the perimeter of the buried structure are the same as the responses of the buried structure strengthened by the RPF layer covering only the wall of the buried structure facing the explosive.

- Based on the 2-D FEA, when the thickness of the RPF exceeds $100 \mathrm{~cm}$ there is no change in the response of the buried structure.

However, the rigid polyurethane foam (RPF) layer could be used as structural retrofitting to absorb the energy of the blast wave propagation hitting the sandwich steel structures.

\section{References}

- Aimone C. T. 1982. Three-Dimensional Wave Propagation Model of Full-Scale Rock Fragmentation. Ph.D. Thesis, Northwestern University.

- Baker W. E., Cox, P. A., Kulesz, J. J. and Strehlow, R. A. 1983. Explosion Hazards and Evaluation, Elsevier.

- Beshara F.B.A. 1994. Modeling of blast loading on aboveground structures -I. Internal blast and ground shock, Comp. \& Structure Vol. 51, No.5.

- Cavalaro S. H. P., Blom C. B. M., Walraven J. C., and Aguado A. 2011. 14-Structure analysis of control deficiencies in segmented lining. Tunneling and Underground Space Technology Vol. 26. pp. 115-127. Elsevier Ltd. 
- Chen, W.F., Mizuno, E. 1990. Nonlinear analysis in soil Mechanics. Elsevier Science Publishers B.V. Netherlands.

- Chen H. (Roger) and Chen S. 1996. Dynamic responses of shallow-buried flexible plates subjected to impact loading. Journal of structure engineering. January 1996. pp. 55-60.

- Darabi A., Ahangari Kaveh A., Noorzad A., and Arab A. 2012. Subsidence estimation utilizing various approaches - A case study: Tehran No. 3 subway line. Tunneling and Underground Space Technology. Vol. 31. pp. 117-127. Elsevier Ltd.

- Dharmasena K. P., Wadley H. N., Xue Z., John W. Hutchinson J. W. 2008. Mechanical response of metallic honeycomb sandwich panel structures to high-intensity dynamic loading International Journal of Impact Engineering 35 (2008) 1063-1074.

- Elsayed A. A. 2011. Study of Rock-Lining Interaction for Circular Tunnels Using Finite Element Analysis", Proceeding of the Jordan Journal of Civil Engineering. Vol. 5. pp. 50 - 64.

- Fayad, H. M. 2009. The Optimum Design of the Tunnels Armoured Doors under Blast Effects. Ph. D. Thesis. Military Technical College (MTC). Cairo

- Gaissmaiere, A. E. W. 2003. Aspects of thermobaric weapon. ADF Health, Vol. 4, pp. 3-6.

- Garner C. and Coffman R. 2013. Subway tunnel design using ground surface settlement profile to characterize an acceptable configuration. Tunnelling and Underground Space Technology Vol. 35, pp. 219- 226. Elsevier Ltd.

- Guowei M., Hongyuan Z., Yong L., and Karen C. 2010. In-structure shock of underground structures. Journal of Engineering Structures. Vol. 32. pp. 3836-3844.

- Gustafsson, R. 1973. Swedish Blasting Technique. Gothenburg, Sweden, SPI.

- Ha J., Yi N., Choi J., and Kim J. 2011. Experimental study on hybrid CFRP-PU strengthening effect on RC panels under blast loading. Journal of composite structures 93. 2070-2082.

- Hao, H., Ma, G. W. and Zhou, Y. X. 1998. Numerical Simulation of Underground Explosions. Fragblast the Int. J. of Blasting and Fragmentation, 2, pp. 383-395.

- Jongpradist P., Kaewsri T., Sawatparnich A., Suwansawat S., Youwai S., Kongkitkul W., and Sunitsakul. J. 2013. Development of Tunnelling influence zones for adjacent pile foundations by numerical analysis. Tunnelling and Underground Space Technology. Vol. 34. pp. 96- 109. Elsevier Ltd.

- Kivi A. V., Sadaghiani M. H., and Ahmadi M. M. 2012. Numerical modeling of ground settlement control large span underground metro station in Tehran metro using central beam column (CBC). Tunnelling and Underground Space Technology. Vol. 28. pp. 218- 228. Elsevier Ltd.

- National Authority for Tunnels (NAT). 1993. Project document of the Greater Cairo metro tunnel (Line 2). Cairo. Egypt.

- National Authority for Tunnels (NAT). 1999. Project document of El-Azhar road tunnels. Cairo. Egypt.

- National Authority for Tunnels (NAT). 2010. Project document of the Greater Cairo metro tunnel (Line 3). Cairo. Egypt.

- Liu, L. and Katsabanis, P. D. 1997. Development of a Continuum Damage Model for Blasting Analysis. Int. J. Rock Mech. Min. Sci., 34, pp. 217-231.

- Liu Jiangfeng, Qi Taiyue, and Wu Zhanrui. 2012. Analysis of ground movement due to metro tunnel station driven with enlarging shield tunnels under building and its parameter sensitivity analysis. Tunnelling and Underground Space Technology Vol. 28, pp. 287- 296. Elsevier Ltd.

- Lu Y., Wang Z., and Chong K. 2005. A comparative study of buried structure in soil subjected to blast load using 2-D and 3-D numerical simulations. Journal soil dynamics and earthquake engineering 25. 275-288.

- Luccioni B., Ambrosini D., Nurick G., and Snyman I. 2009. Craters produced by underground explosions. Journal of computers and structures. Vol. 87. 1366- 1373.

- Mohamad, L. S. 2006. Study and design of fortified structures due to blast effects. M. Sc thesis. Military Technical College (MTC). Cairo. Ammunition and Explosives. In document: AC/258-D/258, Brussels, Belgium. 
- Remennikov, A. 2003. A review of methods for predicting bomb blast effects on buildings. Journal of battlefield technology, Vol. 6, No. 3. pp. 155- 161.

- Schueller, C. T. 1991. Structural Dynamics. Springer-Verlag, Berlin, New York, ISBN 0387-53593-4.

- Smith P. D. and Hetherington J.G. 1994. Blast and ballistic loading of structures. Butterworth-Heinemann Ltd. UK.

- Technical Manual TM 5-885-1. 1986. Fundamentals of Protective Design for Conventional Weapons. Headquarters Department of the Army, Washington DC.

- Technical Manual TM 5-1300. 2008. Structures to Resist the Effects of Accidental Explotions. Unified Facilities Criteria (UFC) .U.S. Army Corps of Engineers; Naval Facilities Engineering Command; Air Force Civil Engineer Support Agency.

- Trelat S., Sochet I., Autrusson B., Cheval K., and Loiseau O. 2007. Impact of a shock wave on a structure on explosion at altitude. Journal of loss prevention on the process industries 20. 509-516.

- Wang Y., Shi J., and Ng C. 2012. Numerical modeling of tunneling effect on buried pipelines. Canadian Geotechnical Journal, pp. 1125-1137, Vol. 48.

- Wu C., Hao H., and Zhou Y. X. 1999. Dynamic Response Analysis of Rock Mass with Stochastic Properties Subjected to Explosive Loads. Fragblast the International J. Blasting and Fragmentation, 3, pp. 137-153.

- Zhang W. and Valliappan S. 1990. Analysis of Random Anisotropic Damage Mechanics Problems of Rock Mass, Part II: Statistical Estimation. Rock Mechanics and Rock Engineering, 23, pp. 241-259. 
Table 1: Geotechnical Parameters of surrounding sand soil media

\begin{tabular}{|l|c|}
\hline Bulk Density $\gamma_{\mathrm{b}}\left(\mathrm{t} / \mathrm{m}^{3}\right)$ & 1.9 \\
\hline Drained Poisson's Ratio $v_{\mathrm{s}}$ & 0.3 \\
\hline Effective Angle of Initial Friction $(\phi)^{\circ}$ & 38 \\
\hline Effective Cohesion C $\left(\mathrm{t} / \mathrm{m}^{2}\right)$ & 0 \\
\hline Modulus Number $(\mathrm{m})$ & 800 \\
\hline Exponent Number $(\mathrm{e})$ & 0.5 \\
\hline Coefficient of Lateral Earth Pressure $\mathrm{K}_{0}$ & 0.38 \\
\hline
\end{tabular}

Table 2: Maximum calculated displacements at point (1) based on different element mesh sizes

\begin{tabular}{|c|c|c|c|c|c|c|c|c|c|c|}
\hline \multirow{2}{*}{$\begin{array}{l}\text { Mesh } \\
\text { Size } \\
(\mathrm{m})\end{array}$} & $\begin{array}{c}\text { Element } \\
\text { size along } \\
\text { outer } \\
\text { boundary } \\
\text { of soil } \\
\text { block mesh }\end{array}$ & \multicolumn{3}{|c|}{$2 \mathrm{~m}$} & \multicolumn{3}{|c|}{$3 m^{*}$} & \multicolumn{3}{|c|}{$5 \mathrm{~m}$} \\
\hline & $\begin{array}{l}\text { Element } \\
\text { size } \\
\text { Along inner } \\
\text { boundary } \\
\text { of concrete } \\
\text { block } \\
\text { mesh }\end{array}$ & $1 \mathrm{~m}$ & $1.5 \mathrm{~m}$ & $2.5 \mathrm{~m}$ & $1 \mathrm{~m}^{*}$ & $1.5 \mathrm{~m}$ & $2.5 \mathrm{~m}$ & $1 \mathrm{~m}$ & $1.5 \mathrm{~m}$ & $2.5 \mathrm{~m}$ \\
\hline $\begin{array}{r}\mathrm{N} \\
\text { displac } \\
\text { poin }\end{array}$ & $\begin{array}{l}\text { imum } \\
\text { ent at } \\
\text { l) }[\mathrm{mm}]\end{array}$ & 9.92 & 9.1 & 8.4 & 9.93* & 8.8 & 7.9 & 9.1 & 8.4 & 7.5 \\
\hline
\end{tabular}

*Selected elements size of 2-D finite element analysis 


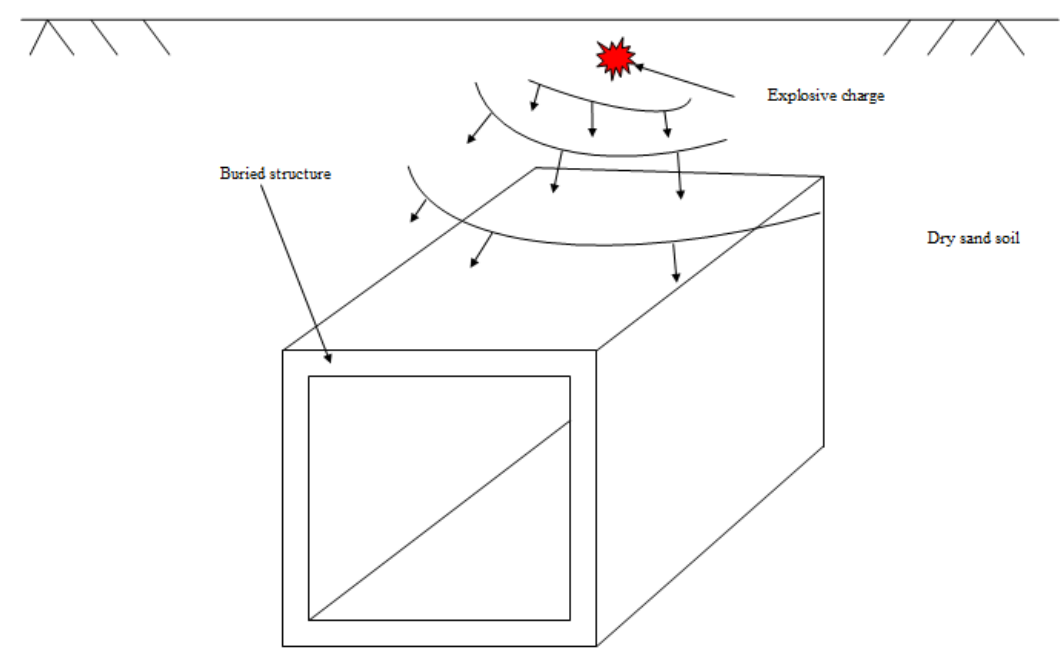

Fig. 1: Diagrammatic scheme of buried structure subjected to blast load

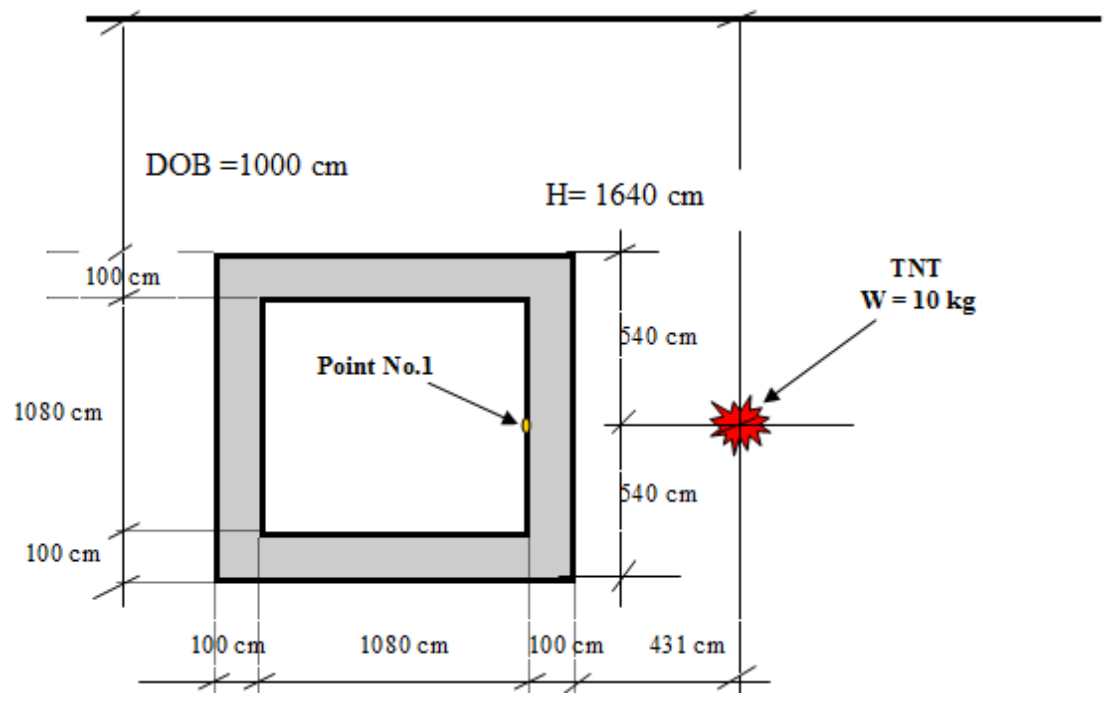

Fig.2: Buried structure subjected to side explosion (after Gouwei et al. 2010)

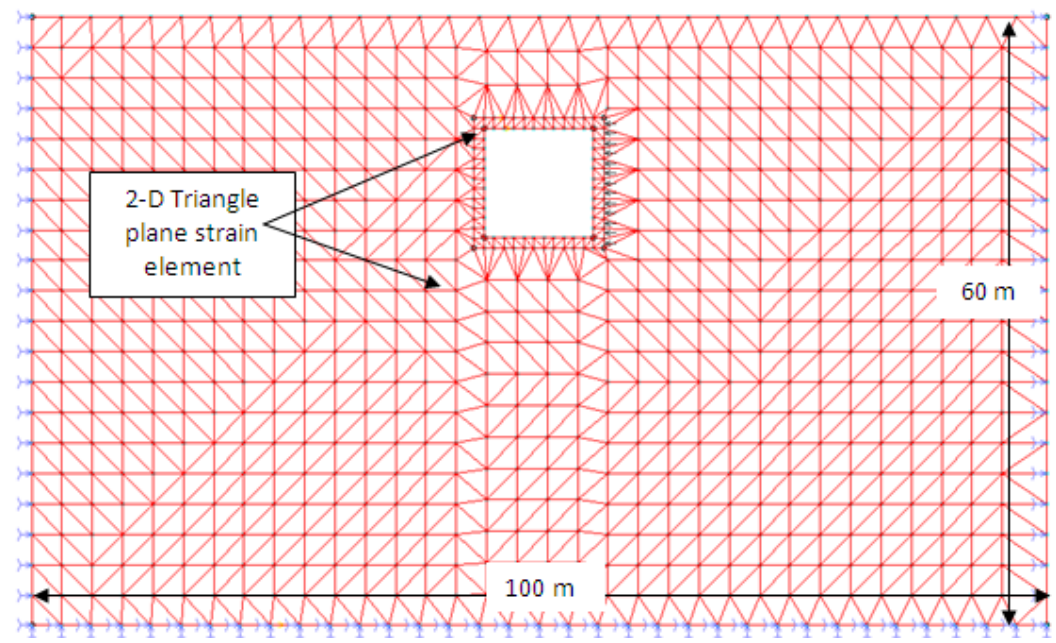

Fig.3: 2-D Finite element model of buried structure 


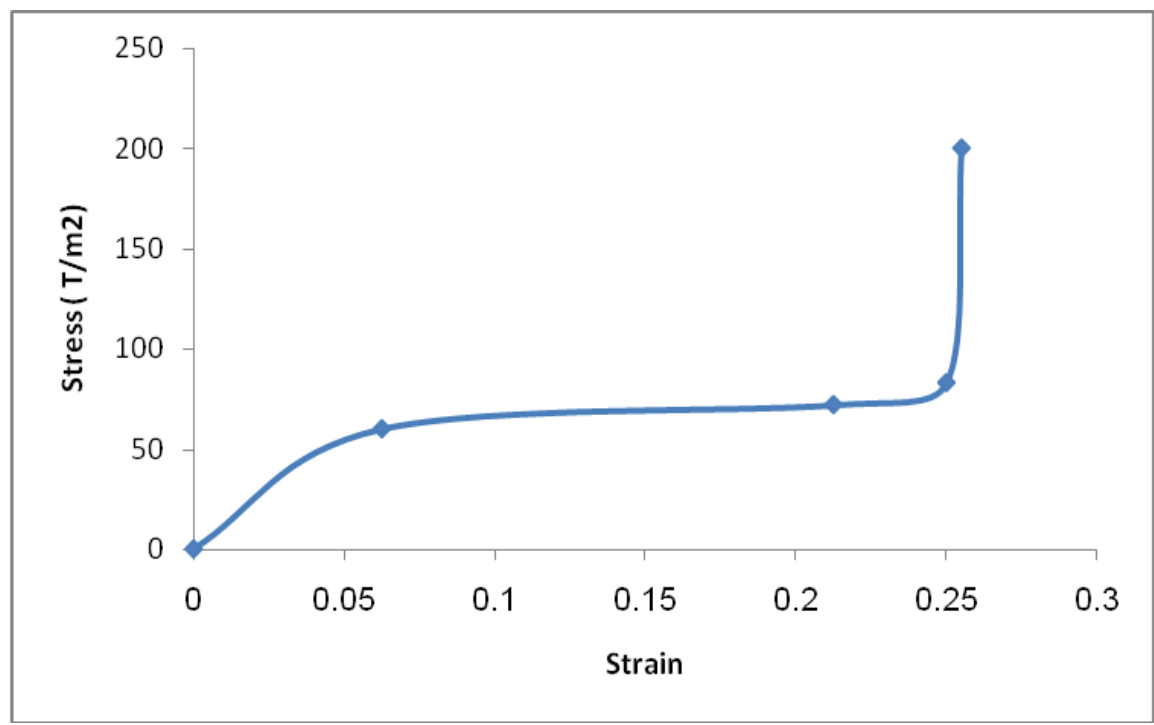

Fig. 4: Stress-strain curve of the rigid polyurethane foam (RPF)

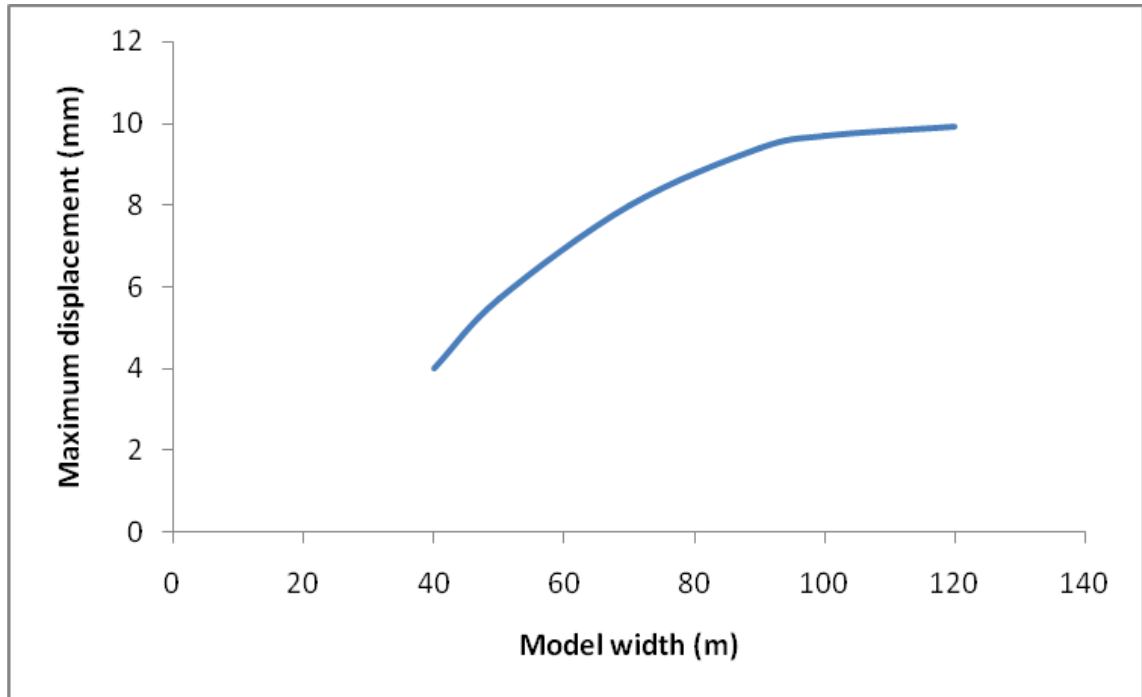

Fig. 5: Calculated maximum displacement at point (1) against different model widths based on blast load

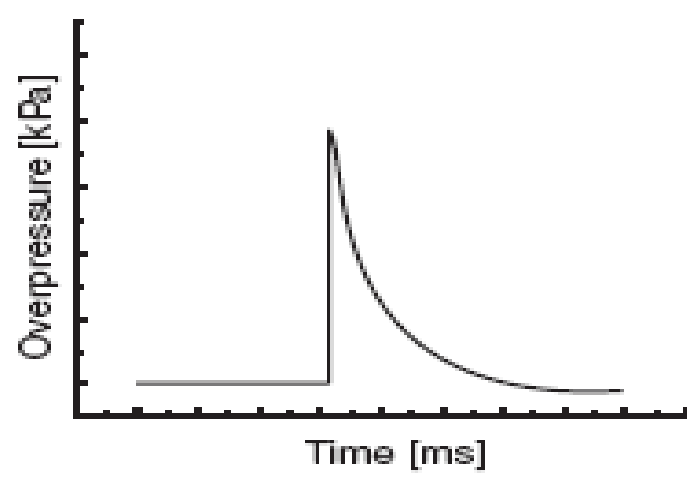

Fig. 6: Typical pressure time history in open air (after Gaissmaire 2003) 


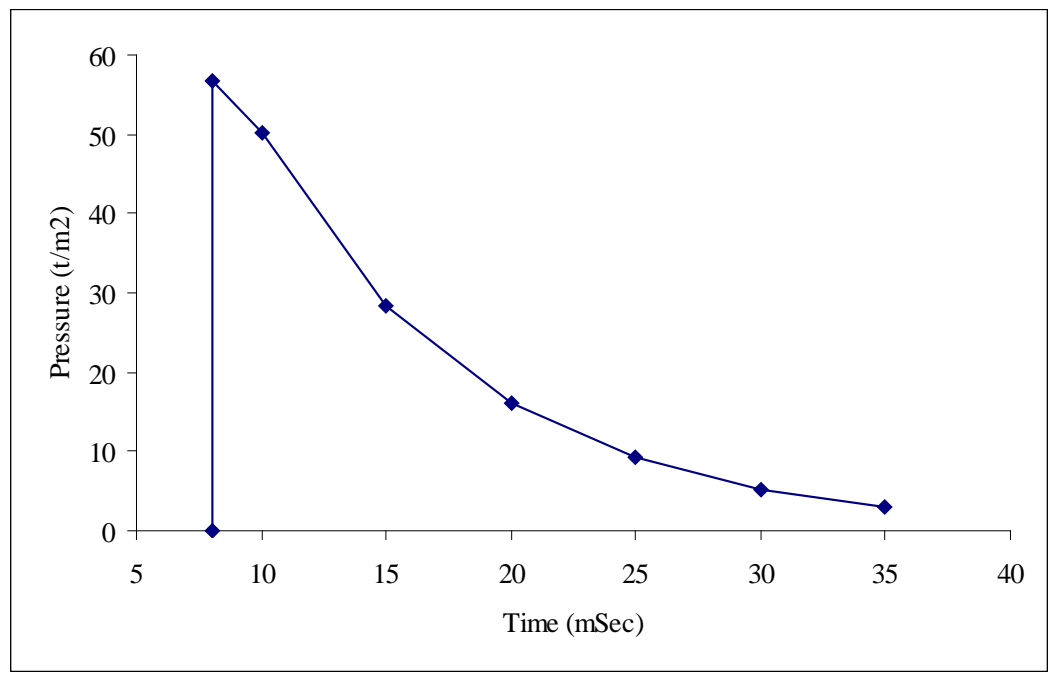

Fig. 7: Pressure-time history hitting buried structure based on 6-kg TNT explosive

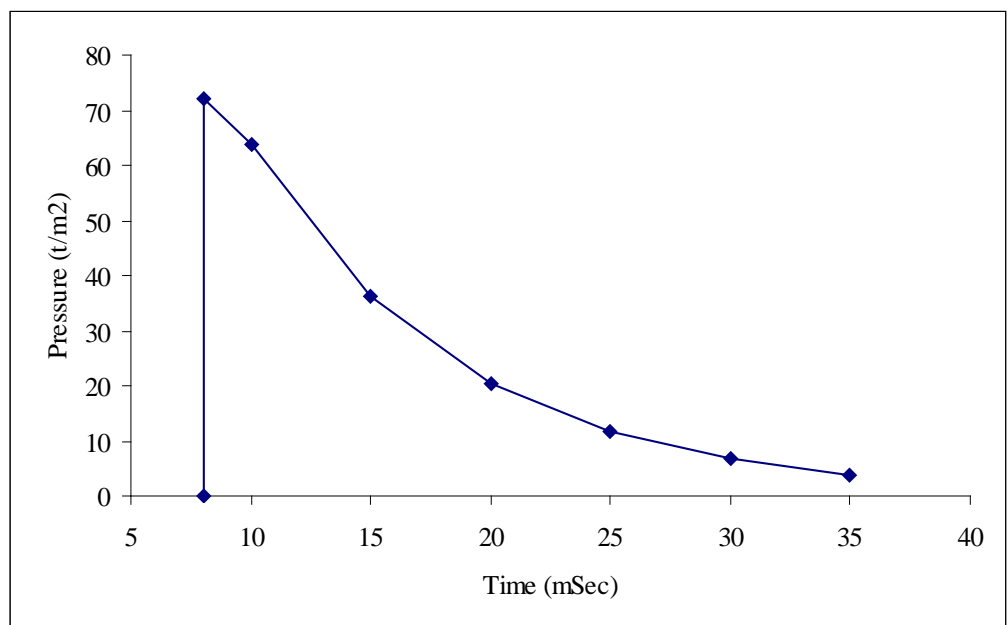

Fig. 8: Pressure-time history hitting buried structure based on 8-kg TNT explosive

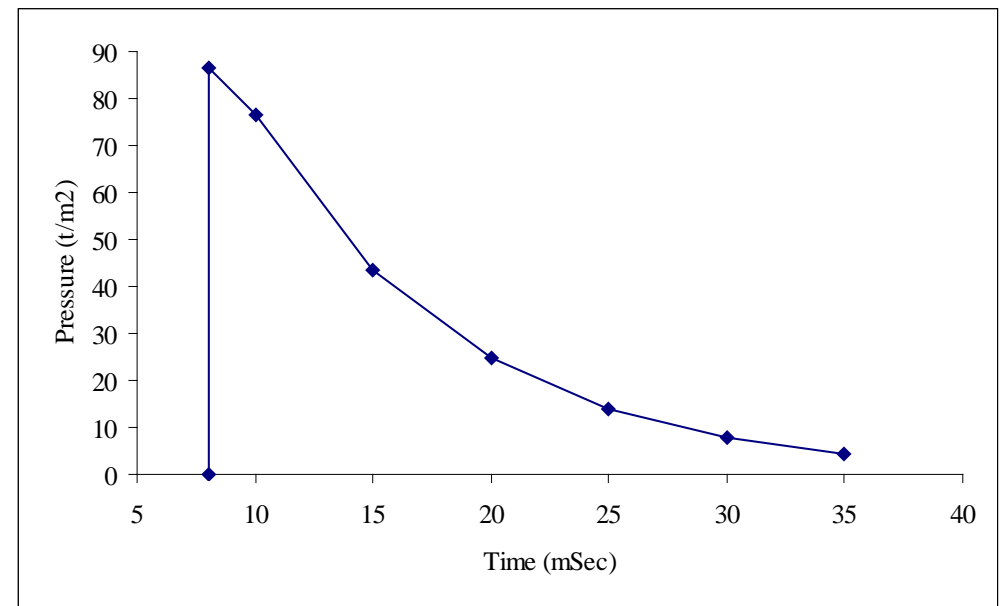

Fig. 9: Pressure-time history hitting buried structure based on 10-kg TNT explosive 


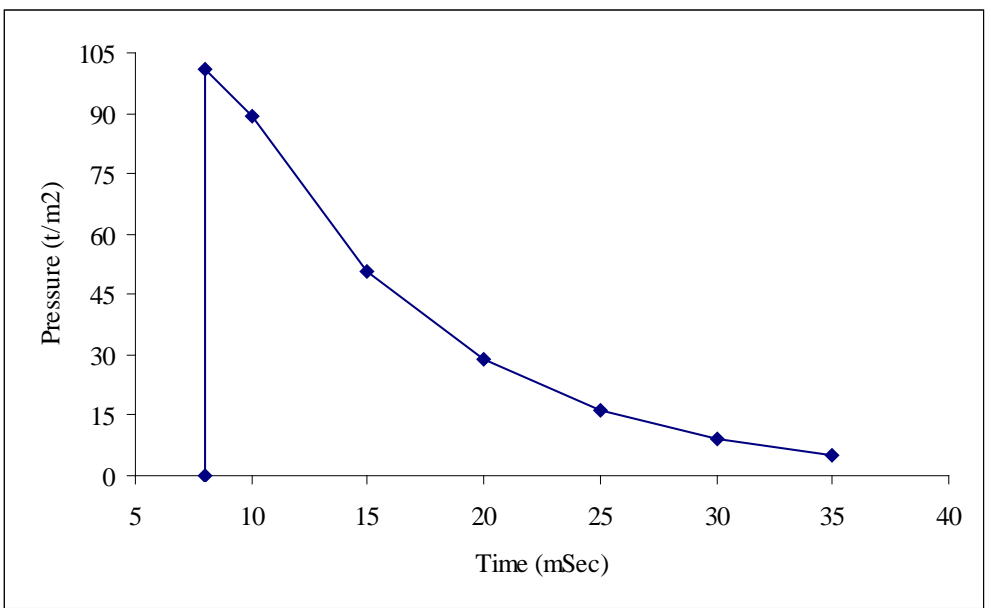

Fig. 10: Pressure-time history hitting buried structure based on 12-kg TNT explosive

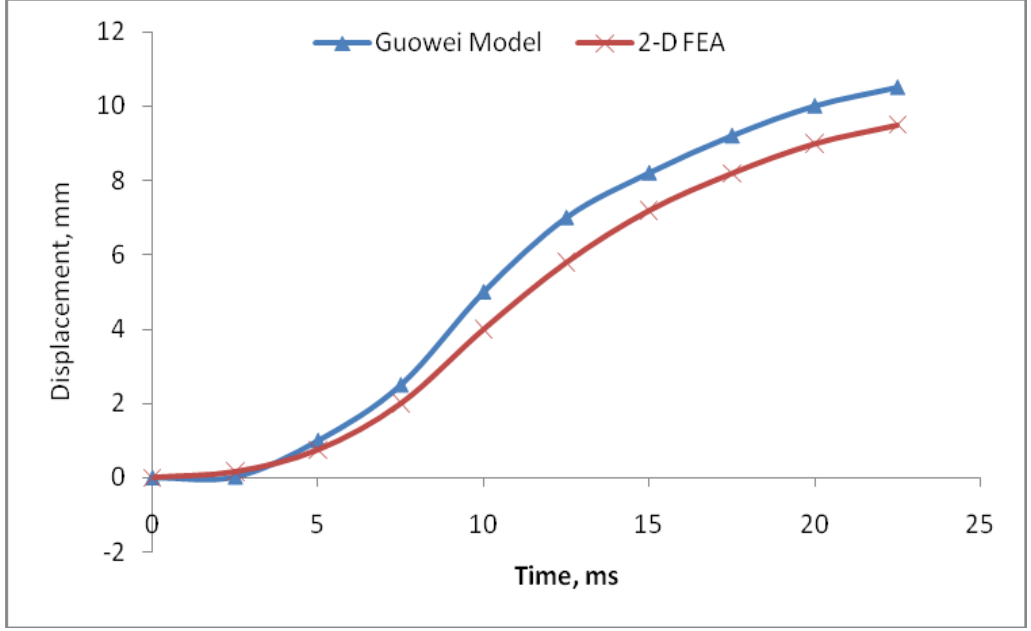

Fig. 11: Displacement-time histories obtained by both the Guowei model and the 2-D FEA at point (1) based on 10-kg TNT explosive

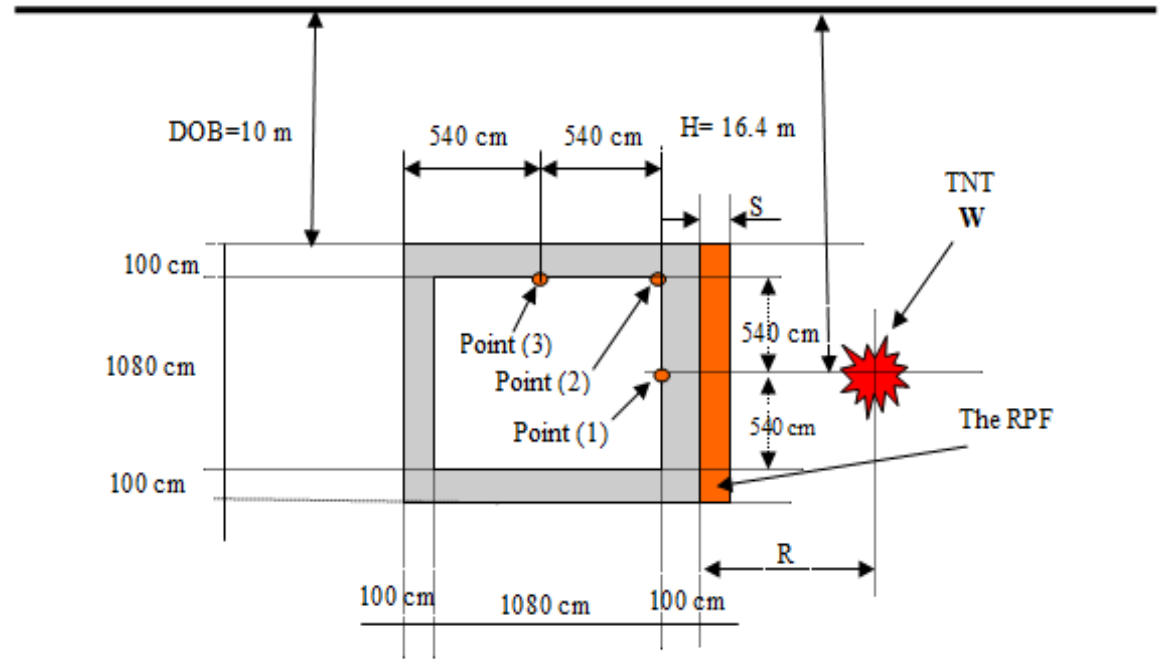

Fig. 12: Diagrammatic scheme shows buried structure strengthened by the RPF layer at the front wall facing side TNT explosive 


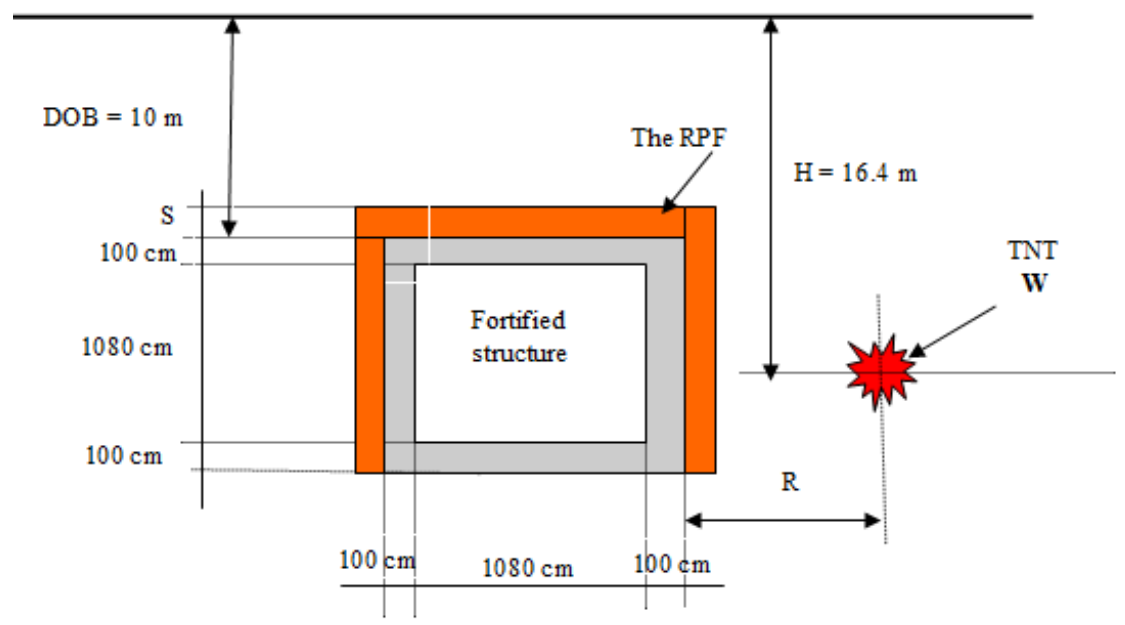

Fig. 13: Diagrammatic scheme shows buried structure strengthened by the RPF layer along perimeter of buried structure subjected to side TNT explosive

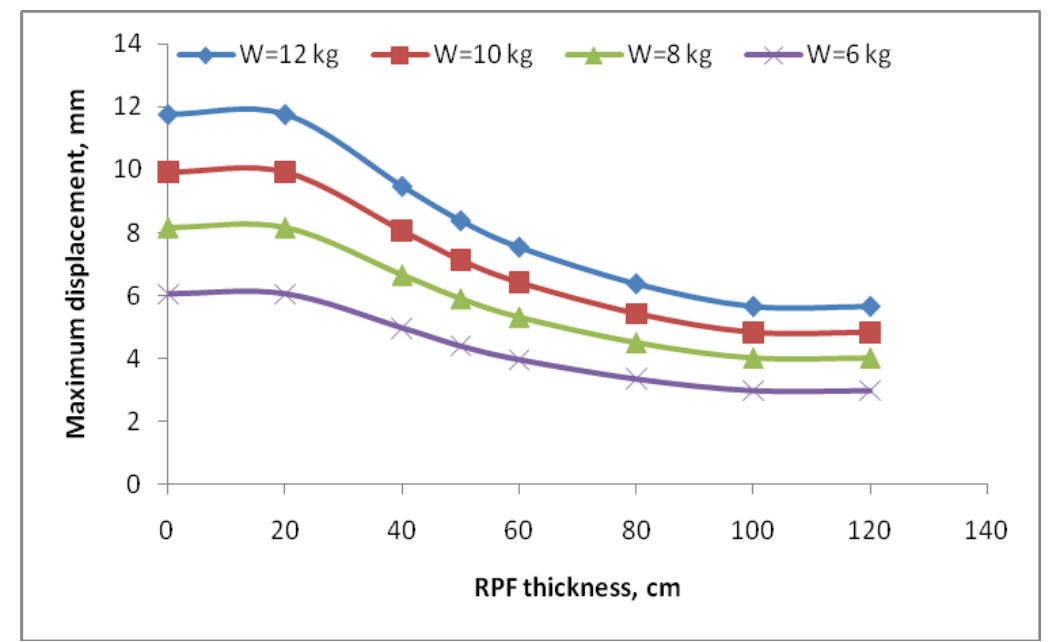

Fig.14: Maximum displacement at Point (1) against different thicknesses of the RPF layer subjected to different TNT explosive charges

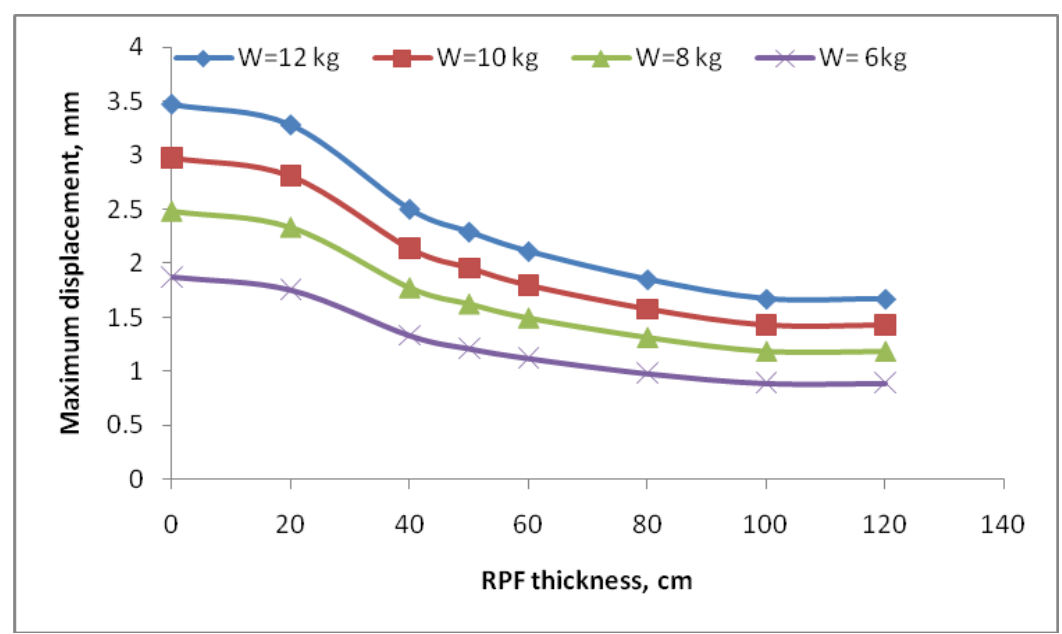

Fig. 15: Maximum displacement at Point (2) against different thicknesses of the RPF layer subjected to different TNT explosive charges 


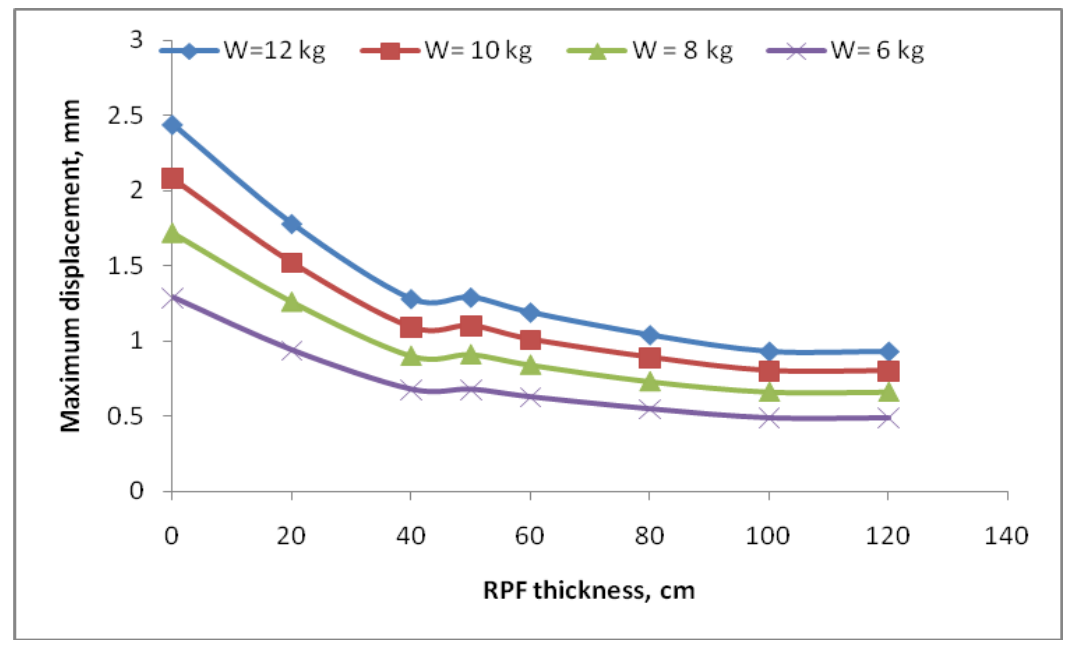

Fig. 16: Maximum displacement at Point (3) against different thicknesses of the RPF layer subjected to different TNT explosive charges

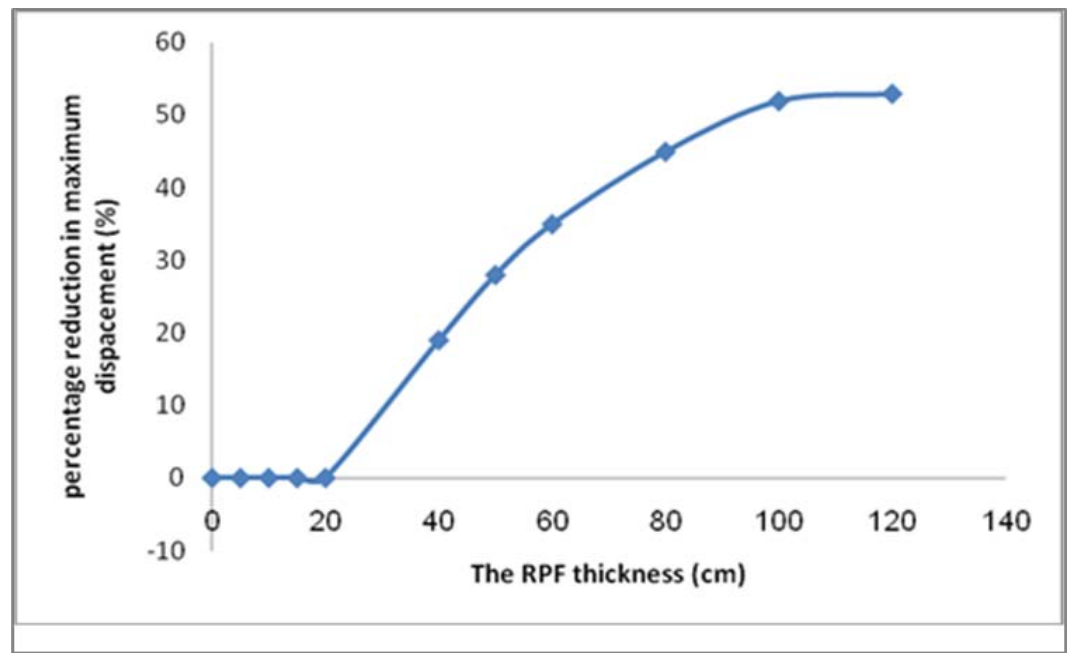

Fig.17: Percentage reduction in maximum displacement of point (1) against different thicknesses of the RPF

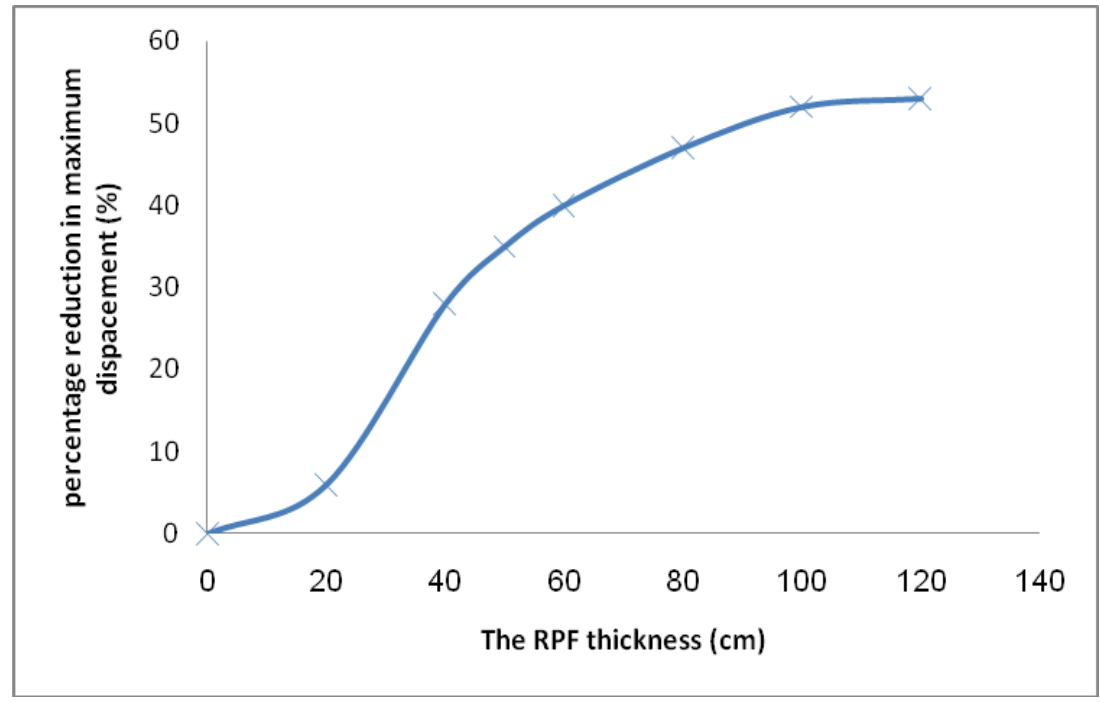

Fig.18: Percentage reduction in maximum displacement of point (2) against different thicknesses of the RPF 


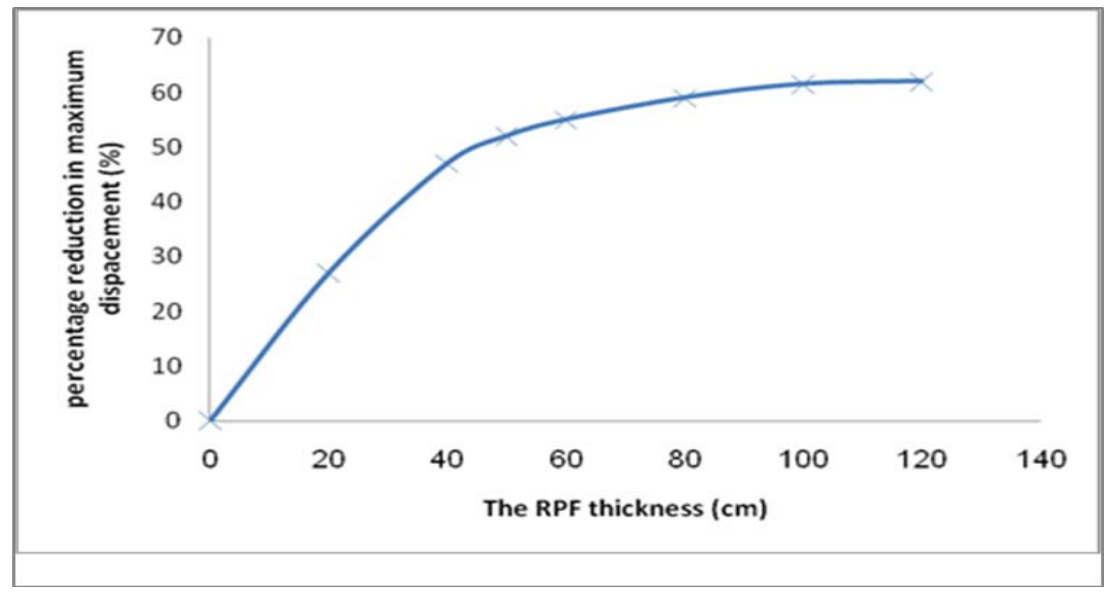

Fig.19: Percentage reduction in maximum displacement of point (3) against different thicknesses of the RPF

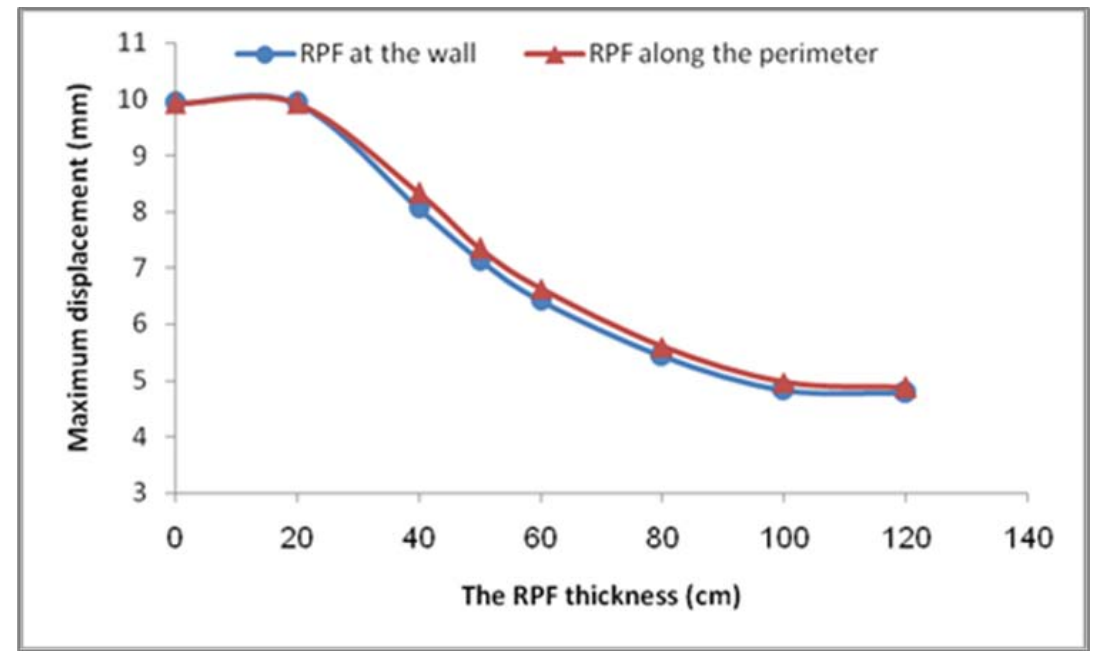

Fig. 20: Maximum displacement of point (1) against different thicknesses of the RPF at 10-kg TNT explosive based on cases (2) and (3)

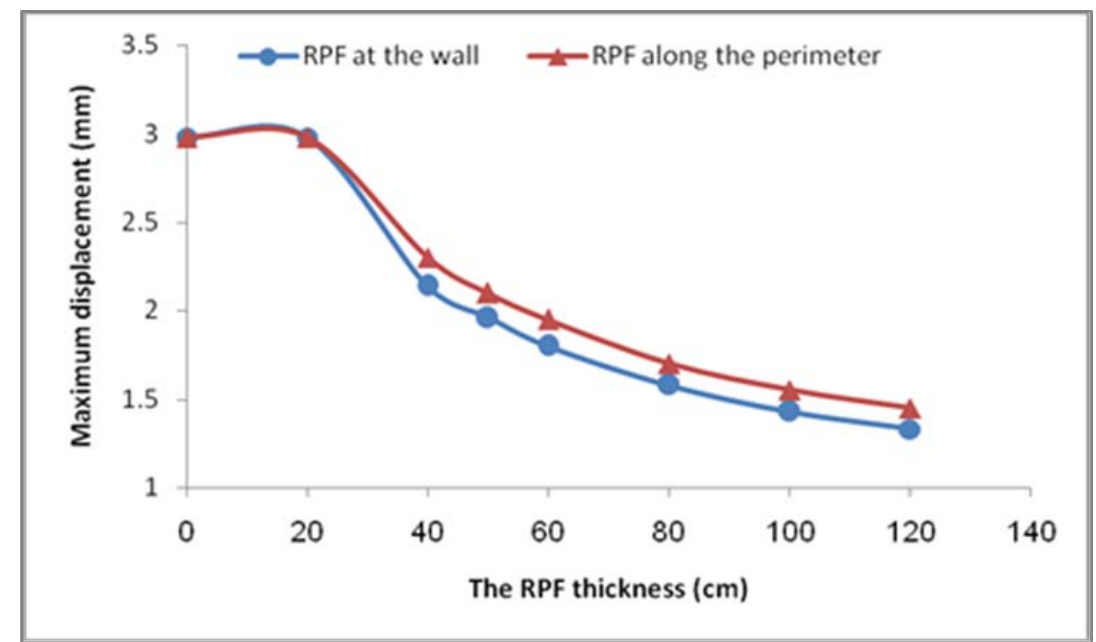

Fig. 21: Maximum displacement of point (2) against different thicknesses of the RPF at 10-kg TNT explosive based on cases (2) and (3) 


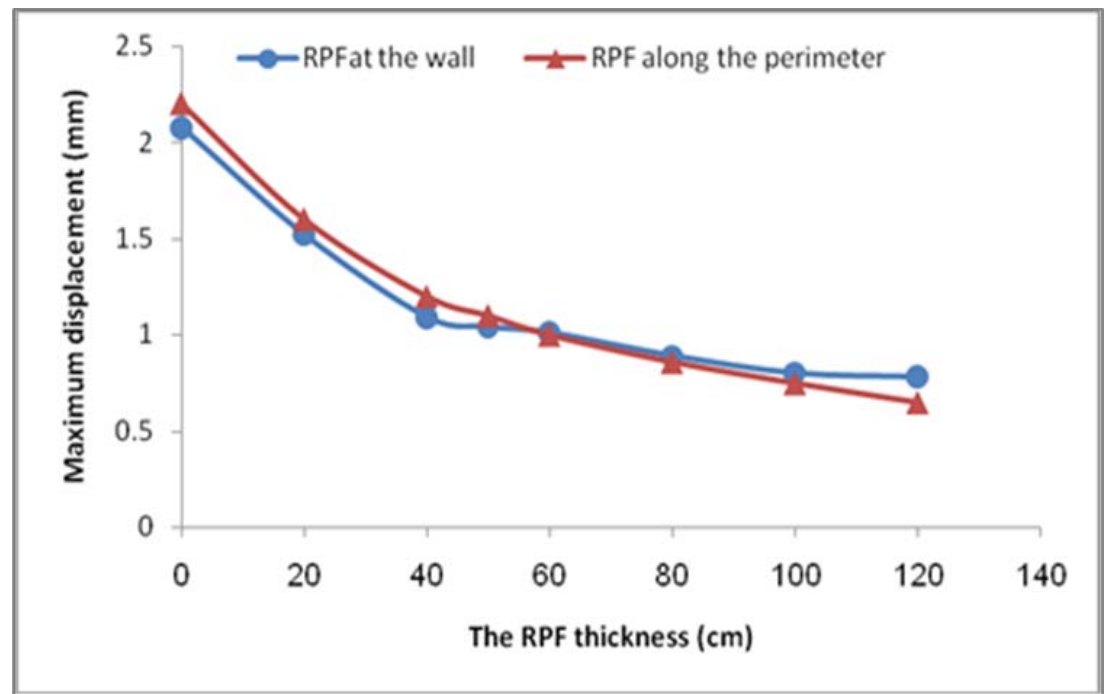

Fig. 22: Maximum displacement of point (3) against different thicknesses of the RPF at 10-kg TNT explosive based on cases (2) and (3) 